\title{
Conglomeration of Uniform Submicrospheres via Sonication. Morphology on Ionic Platinum(II) Complexes of Dodecylmethylbis( $m$-pyridyl)silane
}

\author{
Shin A Kim, Jong Pil Kim, ${ }^{\dagger}$ Young Min Ahn, ${ }_{+}^{\ddagger}$ Jongki Hong, ${ }^{\ddagger}$ and Ok-Sang Jung \\ Department of Chemistrv. Pusan National Chiversity. Pusan 609-735. Korea. * E-mail:oksjungäapusan ack \\ ${ }^{\dagger}$ Korea Basic Science Institute, Pusan 609-735, Korea

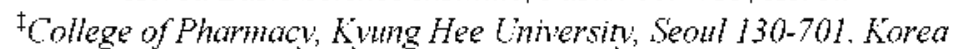 \\ Received January 24, 2008
}

Key Words : Conglomeration. Platinum(II) complexes. SEM image. Submicrospheres

Submicro-scale materials have been utilized in the fabrication of task-specific materials for catalysts, electronic devices, drug-delivery medicines. ceranics, pigments. molecular recognizers. decicants. and cosmetics. ${ }^{1.5}$ Thus. the ability to manipulate the submicro morphology via various factors such as chemical structures. surface properties, and formation condition is emerging as an important field of functional fine materials. ${ }^{6.7}$ Steric effects, surface tension. capillary effects. electric and magnetic forces, permanent dipoles. van der Waals interaction. hydrophilic interactions. surfactant/precursor ratio. covalent bond. and shape anisotropy have been applied as driving forces in the formation of artificial submicro/nano morphology. ${ }^{\$-12}$ Among various morphologies, spherical metal oxides have been widely studied. but the submicrospheres of metal complexes are very rare. ${ }^{13}$ In order to explore the formation and conglomeration of subnicrospheres on ionic platinum(II) complex containing dodecylmethylbis ( $m$-pyridyl)silane (L) without addition of any additives, we carried out the reaction of (dppp)Pt( $\mathrm{PF}$ ) : (dppp: 1.3-bis(diphenylphosphino)propane) with $\mathrm{L}$. The ionic metal complex is interesting in the formation of submicrospheres since they have tractable ampliphilic properties. ${ }^{10}$ Furthermore. the platinum(II) chenistry can be attributed to catalysis and antitumor drugs. ${ }^{1+.15}$

The ionic platinum(II) complex was prepared by the reaction of $(\mathrm{dppp}) \mathrm{Pt}\left(\mathrm{PF}_{6}\right)_{2}$ with $\mathrm{L}$ in a mixture of acetone

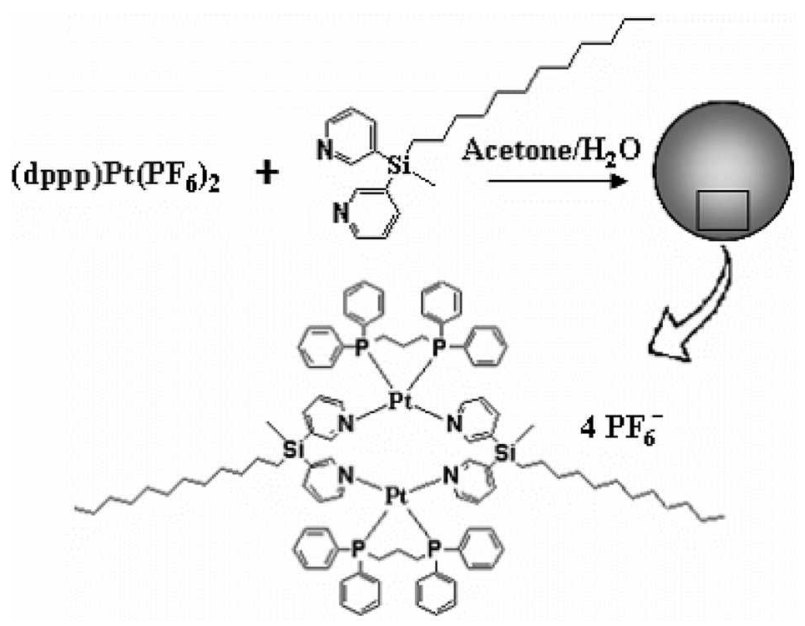

Scheme 1. Formation of submicrospheres. and water as shown in Scheme 1 . In a typical preparation. L $(0.1 \mathrm{mmol}$ ) in $5 \mathrm{~mL}$ of acetone was added slowly to (dppp)$\mathrm{Pt}\left(\mathrm{PF}_{6}\right)_{2}(0.1 \mathrm{mmol})$ in $5 \mathrm{~mL}$ of acetone solution. and then 10 $\mathrm{mL}$ of water was added into the reaction solution. The reaction misture was refluxed for $12 \mathrm{~h}$. and evaporation of acetone at ambient temperature gave a white spherical product of $[(\mathrm{dppp}) \mathrm{Pt}(\mathrm{L})]_{2}\left(\mathrm{PF}_{6}\right)_{4}$ in $81 \%$ yield. The spheres were collected by the filtration using a membrane (membrane filter, Advantec MFS Inc.) for further characterization. The submicrospheres were characterized by ${ }^{1} \mathrm{H}$ NMR, IR $\left(v\left(\mathrm{PF}_{\mathrm{i}}\right)=847 \mathrm{~cm}^{-1}\right)$. contact angle. and SEM along with satisfactory chemical analysis (Supporting Information). The spherical product is a stable solid under air and moisture. In order to measure the molecular weight of the product. the spheres were dissolved in acetone. and then the solution was mixed with 3-nitrobenzyl alcohol (Signa. USA) on a FAB probe tip. The mass fragments indicate that the product is a cyclodimeric structure as depicted in Figure 1 .

SEM images show that the colloidal spheres have diameters in the range of $220-400 \mathrm{~nm}$ (average diameter $=290$ nm) as shown in Figure 2. The submicrosphere (SMS) is hardly soluble in water, but are soluble in a mixture of water and acetone, indicating that the SMS is typical amphiphilic materials. Such an amphiphilic solubility may be a driving force for the formation of spherical morphology. The part around platinum(II) cation and $\mathrm{PF}_{6}{ }^{-}$counteranions seems to be hydrophilic. and L moiety with a new long hydrophobic

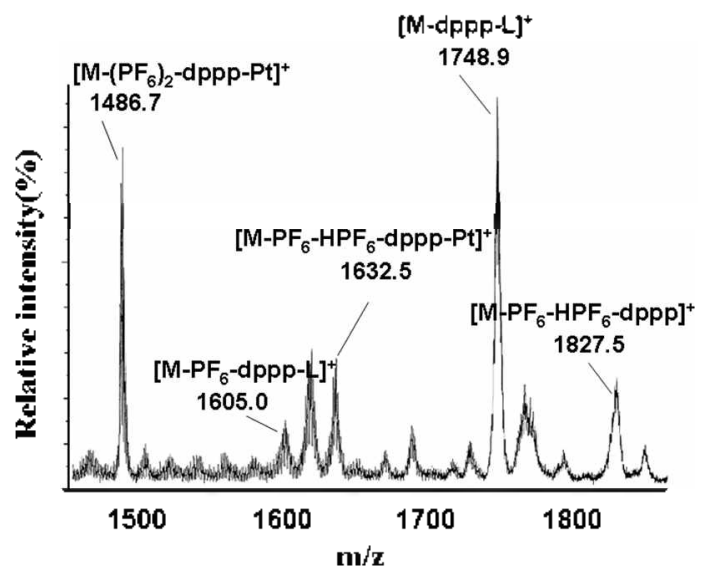

Figure 1. FAB-MS data of $[(\mathrm{dppp}) \mathrm{Pt}(\mathrm{L})]_{2}\left(\mathrm{PF}_{0}\right)_{4}$. 

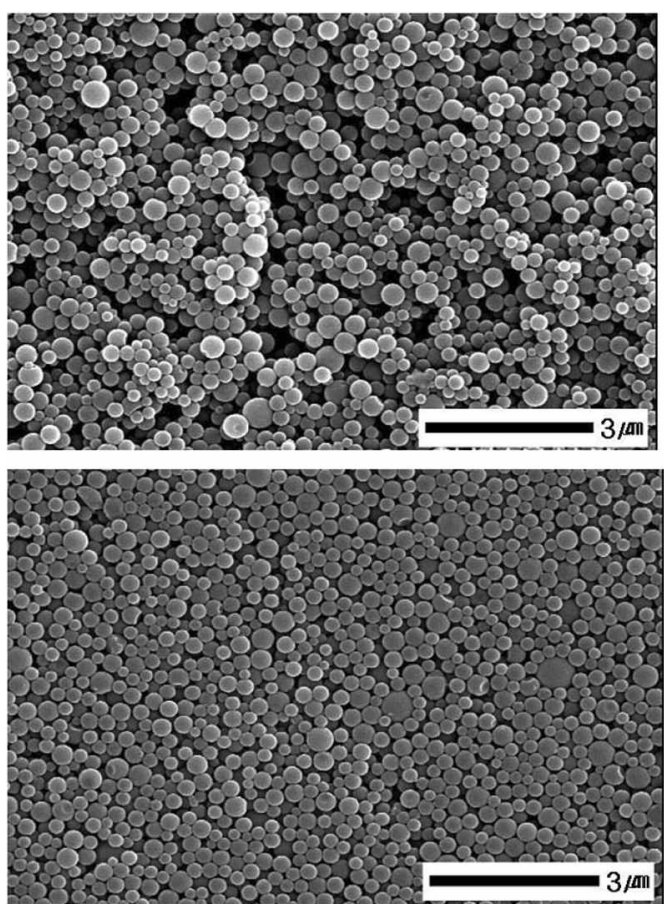

Figure 2. SEM inages of $[(\mathrm{d} p \mathrm{pp}) \mathrm{Pt}(\mathrm{L})]_{2}\left(\mathrm{PF}_{\mathrm{B}}\right)_{4}$ before sonication (top) and after sonication (bottom).

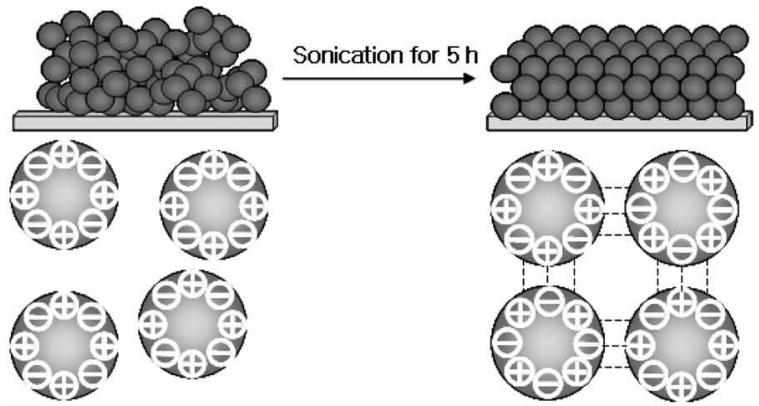

Scheme 2. Electrostatic interactions between cations and anions on the surface of subninicrospheres.

aliphatic chain seems to be hydrophobic. Of course. L itself doesn't show amphiphilic properties and formation of any spherical morphology. The SMS was orderly conglomerated in water suspension by the sonication as shown in Figure 2. indicating the presence of strong interspherical interactions. The conglomerated SMSs are not easily dissociated in water. presumably owing to the presence of electrostatic interactions between anions and cations on the surface of SMS consisting of ionic platinum(II) complexes as shown in Scheme 2. In order to quantify the information on the surface density the contact angle ${ }^{13}$ of a drop of water on the layer of the as-synthesized SMS and the conglonerated SMSs were measured (Figure 3 ). The contact angles of the conglomerated SMSs $\left(112^{\circ}\right)$ are higher than those of the assynthesized SMSs $\left(107-100^{\circ}\right)$. indicating that the layer of the conglonerated SMS surface is significantly compact. Thus. as expected. the contact angle of the as-synthesized SMSs slowly decreases. The contact angle of the layer is depending on the compactness of SMSs.

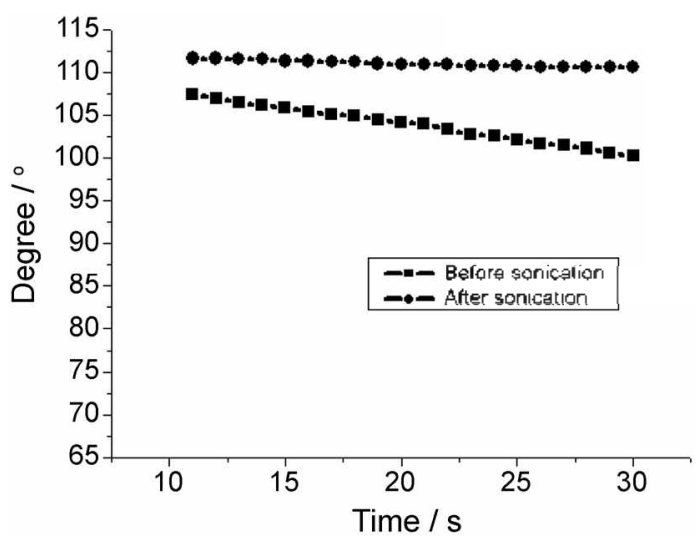

Figure 3. Contact angles of a water-droplet on the layer of submicrospheres.

In conclusion. assembly of ionic platinum(II) complexes with a new long hydrophobic aliphatic chain in a mixture of water and organic solvent was proved to be an effective strategy for the preparation of monodisperse SMS without addition of any template material. This is the first case of the conglomeration of SMS wia sonication. The contact angles could be extrapolated to the degree of compactness of SMS layer. The structural modification via pliability of ionic metal complexes will contribute to the development of more detailed micro-based functional materials such as sensing materials, surface modifiers. and catalysts.

Acknowledgments. This work is supported by the KRF2007-314-C00157.

Supporting Information: ${ }^{1} \mathrm{H}$ NMR, ${ }^{12} \mathrm{C}$ NMR and IR spectra of ligand (L). ${ }^{1} \mathrm{H}$ NMR. ${ }^{12} \mathrm{C}$ NMR and IR spectra of $[(\operatorname{dppp}) \mathrm{Pt}(\mathrm{L})]_{2}\left(\mathrm{PF}_{6}\right)_{4}$

\section{References}

1. Caruso. F.: Caruso. R. A.: Mohwald. H. Science 1998. 282. 1111.

2. Decher. G. Science 1997. 277. 1232.

3. Sur1. S.: Murray. C. B.: Weller. D.: Folks. L.: Moster. A. Science 2000. 287,1989 .

4. Dibben, E. M.: Toublan, F. J.-J.: Suslick. K. S. J. Am. Chem. Soc. 2006. 128,6540 .

5. Jeong. U.: Herricks. T.: Shahar. E.: Xia. Y. J. Am. Chem. Soc. 2005. 127. 1098.

6. Witesides. G. M.: Grzybowski. B. Science 2002. 295. 2418.

7. Yu. S.-H.: Colfen. H.: Antonietti. M. J. Plns. Chem. B 2003. 107 7396.

8. Busch, S.: Dolhaine, H.; DuChesne. A.; Heinz, S.: Hochrein. O: Laeri. F.: Podebrad. O.: Vietze. U.: Weiland. T.: Knief. R. Eim. . Inorg. Chent 1999.643.

9. Mant1. S. Angew: Chent. Int Ed 2000. 39. 3392

10. Yoon. H. J; Chun. I. S.; Na. Y. M; Lee. Y.-A.: Jung, O.-S. Chem. Conm. 2007. 492

11. Reed. C. A. Acc. Chem. Res. $1998,31.133$.

12. Chun1. I. S.: Kwon. T. A.: Yoon. H. T.: Bae. M. N.: Hong. J.: Jung. O.-S. Angew. Chem, hit Ed 2007. +6. 4960 .

13. Chur1. I. S.: Lee. K. S.: Hong. J.: Do. Y.: Tung. O-S. Chem. Lett. 2007. 36, 584

14. Jung. O.S.; Lee, Y. A.: Hark. S. H.: Yoo, K. H. Bull. Chem. Soc. Jpn. $1999,72,2091$.

15. Lee. Y. A.: Jung. O-S. Angew: Chent, Int. Ed 2001. +0.3868. 